\title{
Natural origin scaffolds with in situ pore forming capability for bone tissue engineering applications
}

\author{
Ana M. Martins ${ }^{a, b}$, Marina I. Santos ${ }^{a, b}$, Helena S. Azevedo ${ }^{a, b}$, Patricia B. Malafaya ${ }^{a, b}$, \\ Rui L. Reis ${ }^{a, b, *}$ \\ a 3B's Research Group - Biomaterials, Biodegradables and Biomimetics, Department of Polymer Engineering, University of Minho, Campus de Gualtar, \\ 4710-057 Braga, Portugal \\ ${ }^{\mathrm{b}}$ IBB - Institute for Biotechnology and Bioengineering, PT Government Associated Laboratory, Braga, Portugal
}

Received 4 January 2008; received in revised form 9 June 2008; accepted 13 June 2008

Available online 25 June 2008

\begin{abstract}
This work describes the development of a biodegradable matrix, based on chitosan and starch, with the ability to form a porous structure in situ due to the attack by specific enzymes present in the human body ( $\alpha$-amylase and lysozyme). Scaffolds with three different compositions were developed: chitosan (C100) and chitosan/starch (CS80-20, CS60-40). Compressive test results showed that these materials exhibit very promising mechanical properties, namely a high modulus in both the dry and wet states. The compressive modulus in the dry state for C100 was $580 \pm 33 \mathrm{MPa}$, CS80-20 (402 $\pm 62 \mathrm{MPa})$ and CS60-40 (337 $\pm 78 \mathrm{MPa})$. Degradation studies were performed using $\alpha$-amylase and/or lysozyme at concentrations similar to those found in human serum, at $37^{\circ} \mathrm{C}$ for up to 90 days. Scanning electron micrographs showed that enzymatic degradation caused a porous structure to be formed, indicating the potential of this methodology to obtain in situ forming scaffolds. In order to evaluate the biocompatibility of the scaffolds, extracts and direct contact tests were performed. Results with the MTT test showed that the extracts of the materials were clearly non-toxic to L929 fibroblast cells. Analysis of cell adhesion and morphology of seeded osteoblastic-like cells in direct contact tests showed that at day 7 the number of cells on CS80-20 and CS60-40 was noticeably higher than that on C100, which suggests that starch containing materials may promote cell adhesion and proliferation. This combination of properties seems to be a very promising approach to obtain scaffolds with gradual in vivo pore forming capability for bone tissue engineering applications.
\end{abstract}

(c) 2008 Acta Materialia Inc. Published by Elsevier Ltd. All rights reserved.

Keywords: Natural origin scaffolds; Chitosan; Starch; Enzymes; In situ pore formation

\section{Introduction}

Tissue engineering has recently emerged as a new interdisciplinary science to repair injured body parts and restore their functions by using laboratory-grown tissues, materials and artificial implants. An ideal scaffold to be used for bone tissue engineering should possess characteristics

\footnotetext{
* Corresponding author. Address: 3B's Research Group - Biomaterials, Biodegradables and Biomimetics, Department of Polymer Engineering, University of Minho, Campus de Gualtar, 4710-057 Braga, Portugal. Tel.: +351 253 604781; fax: +351253604498.

E-mail address: rgreis@dep.uminho.pt (R.L. Reis).
}

of excellent biocompatibility, adequate pore size, controllable biodegradability and suitable mechanical properties [13]. The choice of the appropriate fabrication technique is critical because it can significantly influence the properties of the implant and its degradation characteristics. There is, therefore, an increasing need to look for new materials and methodologies to produce scaffolds for bone tissue engineering. One interesting possibility is to develop an in vivo responsive scaffold the properties of which may be regulated by the bone regeneration process, with gradual formation of pores in situ and consequent resorption. This hypothesis seems to be very promising due to the control of degradation in situ and the consequent pore formation, 
which allows the scaffold to have the required mechanical properties during the initial stage of implantation.

One of the present trends in implantable applications is for materials that are derived from nature. Natural origin materials have been demonstrated to promote healing at a faster rate and are expected to exhibit greater compatibility with human tissues. The combination of chitosan with other materials appears to be a common theme in various reports [4,5]. Chitosan is a linear copolymer of $N$-acetylD-glucosamine and D-glucosamine, and is a deacetylated derivative of chitin. The degree of deacetylation (DD) represents the proportion of D-glucosamine units with respect to the total number of units. DD is a structural parameter which influences physicochemical properties [6] such as solubility, crystallinity, swelling behaviour and biological properties [6], namely biodegradation by lysozyme [7,8], wound healing properties [9] and the enhancement of osteogenesis [10]. One interesting feature of chitosan is its cationic nature, resulting from primary amine groups, which allows it to form water-insoluble ionic complexes with a variety of polyanionic substances. It is normally insoluble in aqueous solution above $\mathrm{pH} 7$. However, in weak acids $(\mathrm{pH}<6)$, the free amino groups are protonated and the polymer becomes soluble. Chitosan has been used to induce extracellular matrix formation in tissue regenerative therapy [11]. The degradation of chitosan in the human body has been reported to be carried out by lysozyme $[7,8]$. The degradation kinetics appears to be inversely related to the degree of deacetylation $[8,12]$. Lysozyme, or muramidase, is an enzyme that catalyzes the hydrolysis of the peptidoglycan layer of bacterial cell walls. Human lysozyme is found in various body fluids in concentrations from 7 to $13 \mathrm{mg}^{-1}[13-15]$ in serum and from 450 to $1230 \mathrm{mg} \mathrm{l}^{-1}$ in tears $[13,14]$, saliva $[13,14]$ and other fluids, including those surrounding cartilage [16]. Following implantation of a biomaterial, neutrophils and monocyte-derived macrophages will be present around the foreign material in both the acute and chronic phases of inflammation. A number of enzymes, such as lysozyme, and reactive species will be released from these cells.

Biodegradable starch-based polymeric biomaterials have been studied and proposed for a wide range of biomedical applications. Starch is one of the most abundant naturally occurring polymers, presenting a combination of properties that is steadily increasing its use in several technologies. Starch is a natural polymer that presents excellent characteristics for applications in the biomaterials field, primarily low toxicity [17,18], biodegradability [19] and biocompability [20,21]. It is inexpensive and, above all, reusable. The main enzymes involved in starch degradation are $\alpha$ - and $\beta$-amylase, glucosidase and other debranching enzymes. Starch is hydrolyzed to glucose, maltose and dextrin. It is well known that salivary amylase is involved in the gastric and intestinal digestion of starch in food components. Amylase can also be found in human serum.
The aim of this work was to develop a biodegradable matrix, based in chitosan and native starch, that will form a porous structure in vivo by the preferential attack of the matrix by specific enzymes present in the human body (namely the $\alpha$-amylase and lysozyme). The inclusion of an enzymatically degradable phase in biomaterials may constitute an interesting approach to obtain scaffolds with adequate mechanical properties and with a gradual in situ pore forming ability. Using this innovative methodology, the developed scaffolds can exhibit very promising mechanical properties, due to the absence of macroporosity during the initial stage of implantation. The porosity is developed in situ by enzymes present in human body.

In this work, chitosan/starch scaffolds were developed using a precipitation method. These systems were analyzed in terms of morphology, degradation behaviour and mechanical properties. This study also addressed the effect of leachables from developed scaffolds on the viability of mouse fibroblasts and the influence of the construct's surface on the morphology, adhesion and spreading of fibroblast and human osteoblasts.

\section{Materials and methods}

\subsection{Materials}

Chitosan with medium molecular weight and DD of $92 \%$ (determined by the titration method, as described in Ref. [22]) and native corn starch were purchased from Sigma (St. Louis, USA). Sodium hydroxide $(\mathrm{NaOH})$ and sodium sulphate $\left(\mathrm{Na}_{2} \mathrm{SO}_{4}\right)$ were supplied from Panreac (Barcelona, Spain). $\alpha$-Amylase from Bacillus amyloliquefaciens was obtained by Genencor International, Inc. (Rochester, NY, USA) and egg white lysozyme was from Sigma (St. Louis, USA).

\subsection{Scaffolds preparation}

Finely ground chitosan powder was dissolved in acetic acid $1 \%(\mathrm{v} / \mathrm{v})$ to obtain a $5 \%(\mathrm{w} / \mathrm{v})$ clear solution $(\mathrm{C} 100)$ without any particulate material. Because of the relatively high concentration, these solutions are quite viscous and consequently can be stirred only slightly. However, flow is still observed and it is still possible to inject such viscous solutions to fill out the moulds. Then, using the same procedure, other formulations were prepared with the following ratios: 80/20 chitosan/starch scaffolds (CS80-20) and $60 / 40$ chitosan/starch scaffolds (CS60-40). The solutions were casted into moulds and frozen $\left(-18^{\circ} \mathrm{C}\right)$ overnight. To produce chitosan and chitosan/starch scaffolds, the solutions were immersed in a precipitation solution with containing $0.25 \mathrm{M} \mathrm{NaOH}$ and $0.375 \mathrm{M}$ of $\mathrm{Na}_{2} \mathrm{SO}_{4}$ adapted from Tuzlakoglu et al. [23]. After precipitation, the samples were washed repeatedly with distilled water to remove excess of salts, dried at $37^{\circ} \mathrm{C}$ and followed by successive washings for 5 days until no $\mathrm{pH}$ changes were detected. 


\subsection{Degradation studies}

Degradation studies were carried out by incubating the scaffolds in phosphate buffered saline (PBS) solution ( $\mathrm{pH}$ 7.4) containing $\alpha$-amylase $\left(150 \mathrm{U}^{-1}[15,24]\right)$ and/or lysozyme $\left(13 \mathrm{mg}^{-1}[13-15]\right)$ at concentrations similar to the ones found in human serum, at $37^{\circ} \mathrm{C}$ up to 90 days. A control was also performed by incubating the samples in buffer alone. At the end of the degradation period, the samples were removed and immediately weighed for determination of water uptake, washed thoroughly with distilled water and dried for later calculation of weight loss. Degradation solutions were also analyzed to measure the concentration of reducing sugars, released into the solution as a result of starch hydrolysis by $\alpha$-amylase, using the dinitrosalicylic acid method.

\subsection{Analysis of sample morphology by scanning electron microscopy}

The cross-sections morphology, before and after degradation, was observed by scanning electron microscopy (SEM) in a Leica Cambridge S360. All samples were previously coated with a gold layer (Fisons Instruments, Sputter Coater SC502, UK).

\subsection{Mechanical properties - compression tests}

The mechanical properties of the materials were evaluated on compression tests carried out in the dry and wet state in an Instron 4505 universal mechanical testing machine at a controlled environment $\left(23{ }^{\circ} \mathrm{C}\right.$ and $\left.55 \% \mathrm{RH}\right)$. The crosshead speed was $2 \mathrm{~mm} \mathrm{~min}^{-1}$ until $1 \%$ strain.

\subsection{Cell lines used for biocompatibility testing}

For biocompatibility assessment of the different formulations of the developed scaffolds two different cell types were used: L929 (ECACC, European Collection of Cell Cultures), a mouse fibroblast cell line, and SAOS-2 (ATCC, American Type Culture Collection), a cell line derived from human osteosarcoma. L929 is a cell line commonly used in cytotoxicity testing and osteoblast-like SAOS-2 cells were chosen because they are a model of a relevant cell type for the medical application of the implant. Both cell lines were cultured in Dulbecco's modified Eagle's medium (Sigma, St. Louis, USA), supplemented with 10\% fetal bovine serum (Biochrome) and 1\% antibiotic/antimicotic solution (Sigma, St. Louis, USA). In all the experiments cells were kept in an incubator at constant temperature $\left(37^{\circ} \mathrm{C}\right)$ and $\mathrm{CO}_{2}$ concentration $(5 \%)$.

\subsection{Biocompatibility evaluation: extracts and cell adhesion studies}

In the scope of biocompatibility assessment, and according to ISO norms, two categories of in vitro cytotoxicity assays were performed: extract and direct contact tests. The scaffolds, previously sterilized by ethylene oxide, were extracted in complete culture medium for $24 \mathrm{~h}$ at constant temperature $\left(37^{\circ} \mathrm{C}\right)$ and agitation $(60 \mathrm{rpm})$. L929 cells were seeded in 96-well cell culture plates $\left(10,000 \mathrm{cells} \mathrm{cm}^{-2}\right)$, in order to reach $80 \%$ confluence in $24 \mathrm{~h}$. The extracts were filtered and placed in contact with the monolayer of L929 cells for $72 \mathrm{~h}$. A control, with cells grown in the presence of complete culture medium, was included. Afterwards, the viability test MTT was performed. Briefly, the culture medium was replaced by a solution of MTT and the cells were incubated for $4 \mathrm{~h}$. The viable cells, those with functional mitochondrial dehydrogenase, were able to reduce the yellow MTT into a purple formazan product. The end product was quantified by spectroscopy and the results expressed as percentage of cell viability.

In direct contact test, the developed scaffolds were seeded with L929 cells $\left(8 \times 10^{4} / 50 \mu 1\right)$ and with osteoblast-like cells $\left(5 \times 10^{5}\right.$ cells ml $\left.{ }^{-1}\right)$ for 3 and 7 days. Prior to cell seeding, the chitosan/starch scaffolds were immersed in culture medium overnight. This step is intended to reduce culture medium uptake by the highly hydrophilic materials. After each time point, the samples were fixed with glutaraldehyde, dehydrated, critical point dried and gold sputtered for SEM observation.

\section{Results and discussion}

\subsection{Characterization of the scaffolds morphology}

In this work, degradable scaffolds based on chitosan and native corn starch were developed for use in bone tissue engineering applications. Three different compositions were prepared and tested. Fig. 1 shows the interior morphology of the obtained scaffolds. C100 material exhibits a smooth surface (Fig. 1A), whereas in the micrographs of CS80-20 and CS60-40 scaffolds (Fig. 1B and C) it is possible to observe that the starch granules are distributed homogeneously along the chitosan matrix, as well as incorporated into the matrix. Starch granules have dimensions ranging from 0.5 to $175 \mu \mathrm{m}$ [25], which are mainly dependent upon their origin. SEM micrographs (Fig. 1B and C) show that starch granules from native corn starch have dimensions ranging from 5 to $10 \mu \mathrm{m}$. The proposed processing technique is based on precipitation from a solution. This technique was used with the aim of promoting the ionic complexation. This precipitation method does not allow a macroporous structure to be obtained (Fig. 1). The macroporosity will be formed in situ by enzymes present in human serum.

\subsection{Degradation behaviour}

The main aim of the degradation studies, using $\alpha$-amylase and lysozyme with similar concentrations to the ones found in human serum, is to simulate the physiological conditions and subsequent pore formation. It is expected 

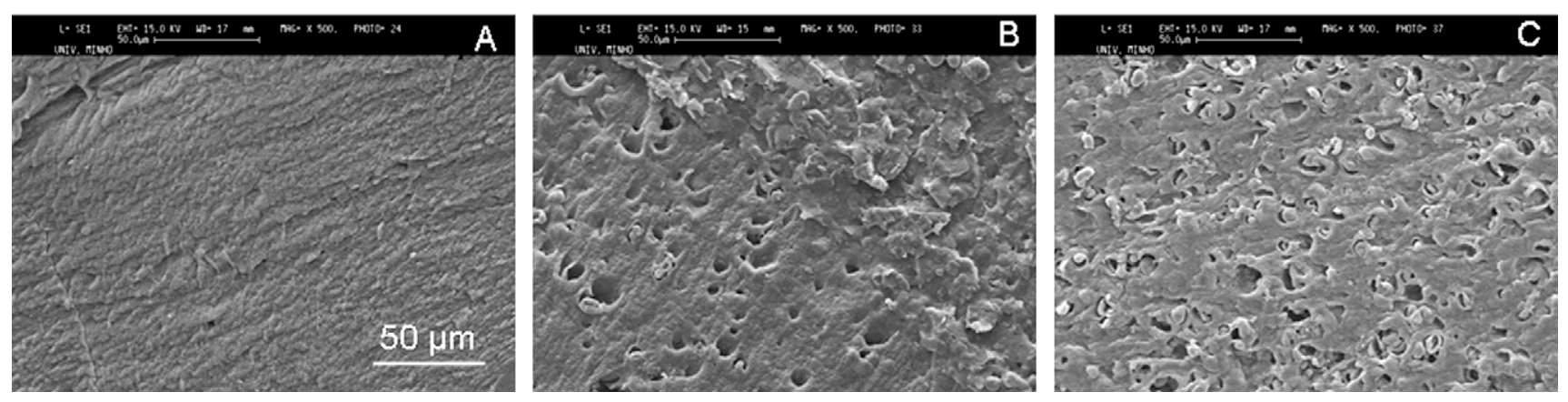

Fig. 1. SEM micrographs of the developed scaffolds (cross-sections) before degradation: (A) C100, (B) CS80-20 and (C) CS60-40. The scale bar is 50 $\mu \mathrm{m}$ and applies to all images.

that this innovative methodology will induce the formation of pores. The pore size and its distribution in the scaffold can be controlled by the location of the "sacrifice" phase (native starch) that will also control the water uptake behaviour due to the different hydrophilic nature of the materials. The hypothesis for this work is related to the formation of pores due to the degradation induced by specific enzymes present in the human body. After implantation, it is expected that a porous structure will be formed in situ, allowing the penetration of the cells deep within these scaffolds.

Concerning the water uptake in PBS, the C100 scaffolds present the highest degree of hydration, of about $140 \%$ (Fig. 2). The ability of a material to retain water and its water permeability are important parameters to be studied, since they will influence the absorption of body fluids and the transfer of cell nutrients and metabolites through the materials. The diffusity of nutrients is a very important parameter since, in an in vivo situation, a porous structure will be formed, created by the activity of enzymes present in the human body, allowing the penetration of cells deep into the scaffolds. As expected, the water uptake of both CS80-20 and CS60-40 is lower than that of $\mathrm{C} 100$, due to the presence of starch, which is less hydrophilic than chitosan (Fig. 2). The weight loss in PBS was not significant (data not shown). The greatest weight

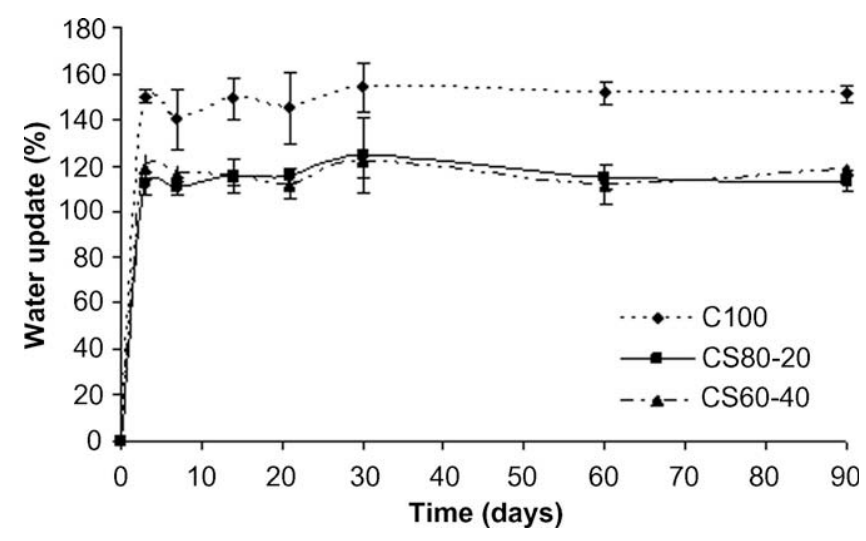

Fig. 2. Water uptake of the scaffolds as a function of immersion time in PBS (pH 7.4, $T=37^{\circ} \mathrm{C}$ ). loss was observed in CS60-40. This finding can be explained by the presence of starch granules distributed in the scaffolds. These results suggest that different percentages of starch influence the degradation rate.

All scaffolds were sectioned to observe the interior morphology and formation of pores induced by enzymatic attack at similar concentrations to those found in human serum. By SEM observation, as expected, the native starch phase (of CS80-20 and CS60-40; Fig. 3C and D) was seen to be attacked in the presence of $\alpha$-amylase. It was also observed that $\alpha$-amylase induced the formation of pores in C100 material (Fig. 3A and B). It was also reported by Muzzarelli et al. [26] that $\alpha$-amylase was able to attack the chitosan material.

In the presence of lysozyme, it was possible to detect the preferential attack of $\mathrm{C} 100$ (Fig. 3E) since this enzyme is able to hydrolyze chitosan in some extent. It is expected that, when the scaffolds are implanted in the body, the chitosan will be degraded gradually by lysozyme and then reabsorbed. Lysozyme is known to be ubiquitous in the body $[13,27]$. The main advantage of biodegradable over non-biodegradable materials is the disappearance of implanted foreign material, which could elicit foreign body reactions from the host's defence system during their long-term contact with a living structure. Since lysozyme is present in cellular lysosomes and lysosomal rupture is associated with inflammation, it has been assumed that the source of the increased lysozyme activity is the release of enzyme from the lysosomes of phagocytic cells [28]. When any material is implanted, an acute inflammatory response will occur, with the consequent $\mathrm{pH}$ decrease and secretion of increased levels of lysozyme. Furthermore, it has been demonstrated that the initial degradation rate of chitosan at $\mathrm{pH} 4.5$ is about five times higher than the rate at $\mathrm{pH} 7.0$ [14]. The results obtained in this work showed the attack of C100 by lysozyme with the consequent formation of pores.

In order to investigate the effect of an enzyme cocktail, containing $\alpha$-amylase and lysozyme, on the overall degradation rate of the materials, as well as on the type of porosity obtained, the materials were also simultaneously incubated with these enzymes. Analyzing the results pre- 

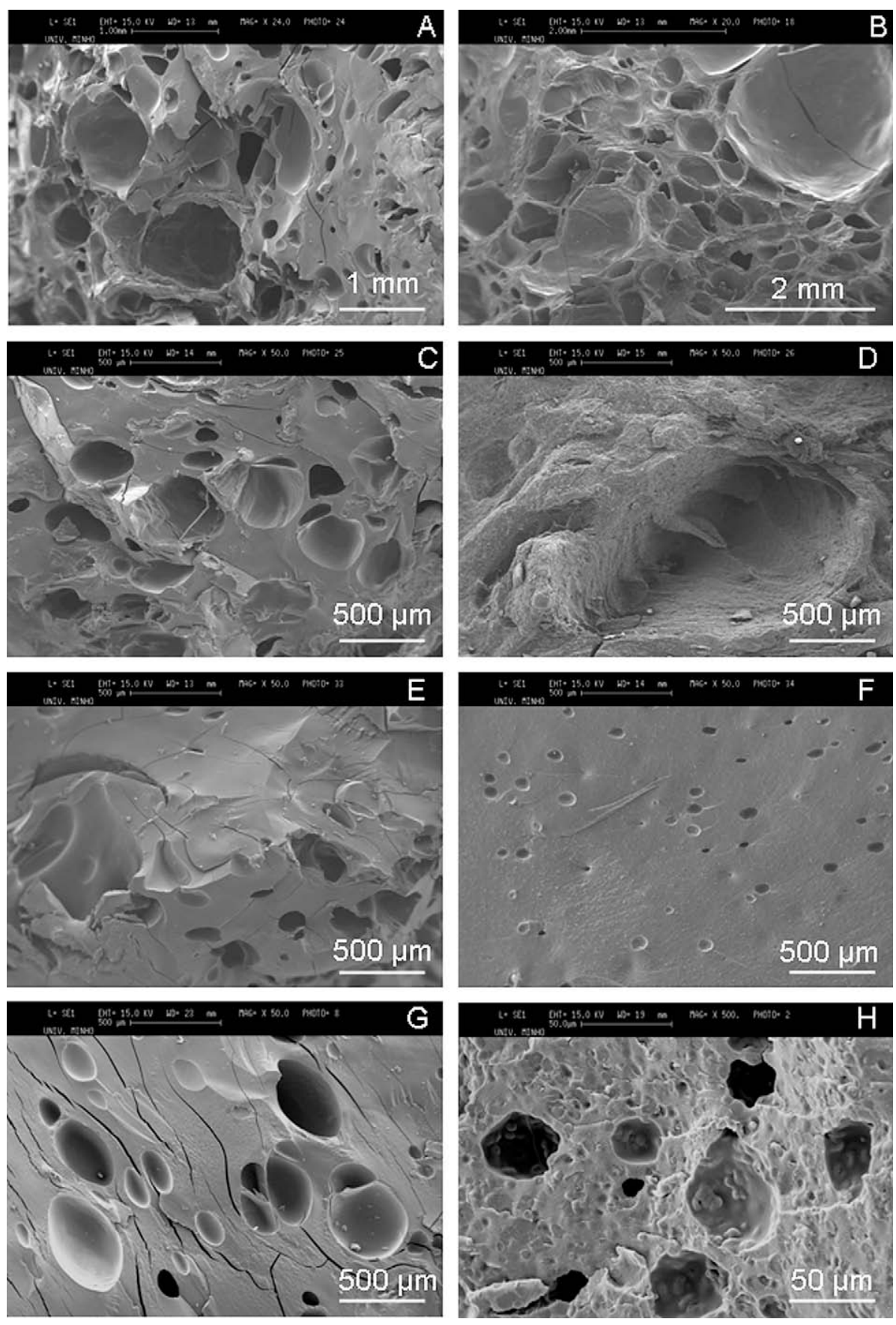

Fig. 3. SEM micrographs showing the morphology of chitosan-based scaffolds after 14 days in PBS with $\alpha$-amylase solution (A, C100; C, CS80-20; D, CS60-40); after 30 days in same solution (B, C100); after 14 days in PBS with lysozyme solution (E, C100; F, CS80-20); and in the same period in PBS with $\alpha$-amylase and lysozyme solution (G, C100; H, CS60-40).

sented in Fig. 4, it is possible to observe that CS60-40 showed the highest weight loss compared with CS80-20 and $\mathrm{C} 100$. The greater susceptibility of CS60-40 to enzymatic degradation may be related to the presence of a higher surface area for preferential attack, due to the interface between the two components. SEM micrographs (Fig. $3 \mathrm{G}$ and $\mathrm{H}$ ) show that enzymatic degradation caused a porous structure is formed. Some studies showed that pore sizes less than $15-50 \mu \mathrm{m}$ result in fibrovascular ingrowth, pore sizes of $50-150 \mu \mathrm{m}$ encourage osteoid for- mation, and pore sizes greater than $150 \mu \mathrm{m}$ encourage the ingrowth of mineralized bone [29].

Since the formation of pores in the presence of lysozyme was not so pronounced compared to those obtained with $\alpha$ amylase or the two enzymes together ( $\alpha$-amylase and lysozyme), it may be necessary to look for alternative strategies to enhance the scaffold degradation. One possible alternative could be the incorporation of lysozyme in higher concentrations at the surface of these materials. This could be achieved by incorporation of the enzyme into biomimetic 


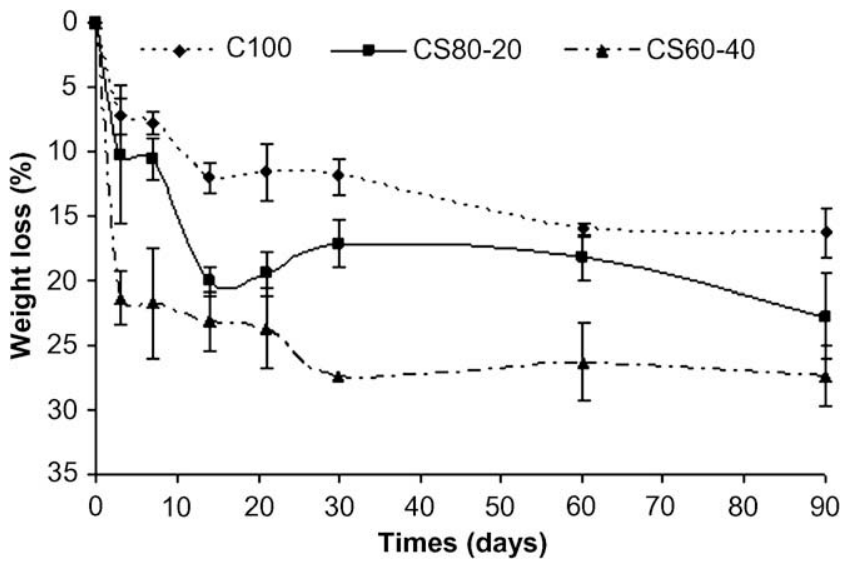

Fig. 4. Weight loss of chitosan/starch scaffolds as function of time in PBS with $\alpha$-amylase $\left(150 \mathrm{U}^{-1}\right)$ and lysozyme $\left(13 \mathrm{mg} \mathrm{l}^{-1}\right)\left(\mathrm{pH} 7.4, T=37^{\circ} \mathrm{C}\right)$.

calcium phosphate $(\mathrm{CaP})$ coatings that are generated at physiological conditions. By using this system it may be possible to enhance the in vivo performance of the scaffolds by conferring osteoconductive properties to the material. Several papers report the incorporation of enzymes or bioactive agents into $\mathrm{CaP}$ coatings in order to promote their degradation and/or their osteoconductive/osteoinductive potential [30-32]. It is also expected that in an in vivo situation the pore formation will occur more rapidly due to the inflammatory response, which will induce a $\mathrm{pH}$ decrease and cause increased levels of lysozyme to be released by several groups of cells, such as neutrophils, monocytes and macrophages.

After enzymatic degradation a porous structure was observed to have been formed, indicating the potential of this methodology to obtain in vivo scaffolds with pore forming ability for bone tissue engineering applications.

The formation of pores in vitro in the presence of enzymes at a similar concentration to those found in human plasma is evident, although pore formation is expected to occur more rapidly in vivo, due to the presence of other enzymes and cells.

\subsection{Mechanical properties}

A hard material, with a high initial mechanical strength and an adequate degradation rate, is normally required for bone tissue engineering applications. The results of the compressive tests showed that these materials exhibit very interesting mechanical properties in the dry and even in the wet state. The highest compressive modulus was observed for C100 $(580 \pm 33 \mathrm{MPa})$ in the dry state. For CS80-20 and CS60-40, the compressive moduli in the dry state were $402 \pm 62$ and $337 \pm 78 \mathrm{MPa}$, respectively (Fig. 5). The values found are higher than the typical values presented for chitosan-based materials. The modulus decreased with increasing amounts of starch present in the scaffolds. This could be due to the poor adhesion between the phases, since it is a physical mixture, i.e. the

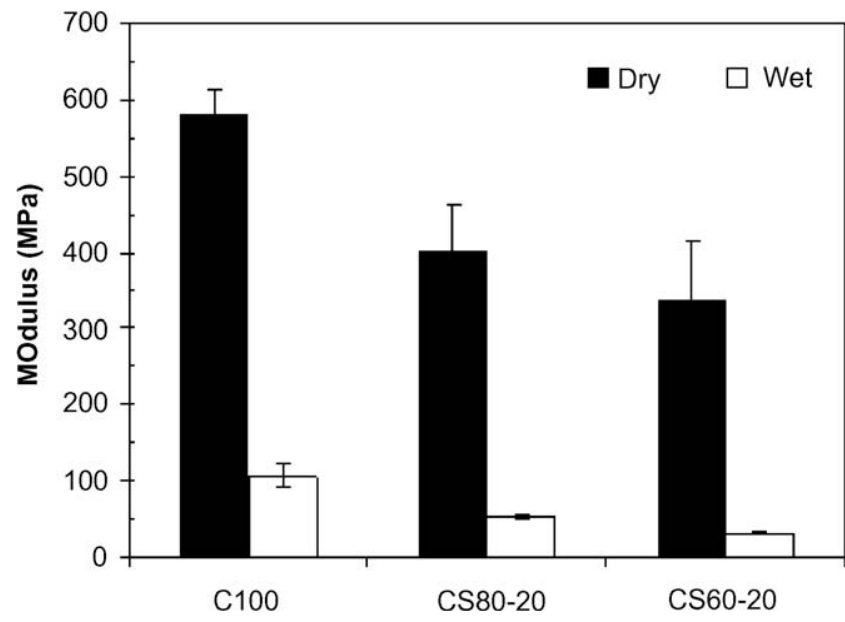

Fig. 5. Results of the compression tests: modulus in dry and wet state.

"sacrifice" phase is acting as nucleation site for fracture propagation. In the wet state, the same tendency was observed, but the values were lower, as expected $(\mathrm{C} 100$, $107 \pm 15 \mathrm{MPa}$; CS80-20, $53 \pm 3 \mathrm{MPa}$; CS60-40, 31 $\pm 1 \mathrm{MPa}$; Fig. 5). The mechanical properties exhibited by the scaffolds in the wet state fall within the normal ranges of strength and modulus for trabecular bone, which are about $0.02-0.5 \mathrm{GPa}[1,3]$ for the compressive modulus and 2 $12 \mathrm{MPa}[1,3]$ for strength.

\subsection{Cytotoxic assessment of the extracts}

In order to evaluate the cytotoxicity of the substances that leach out of the developed scaffolds, a viability assay (the MTT test) was performed. This test is based on mitochondrial viability, as only functional mitochondria can oxidize the MTT solution, giving a typical blue-violet end product. Fig. 6 shows that for CS80-20 and CS60-40 the percentage of viable cells was around $100 \%$, thus comparable to the control. On the other hand, the value of via-

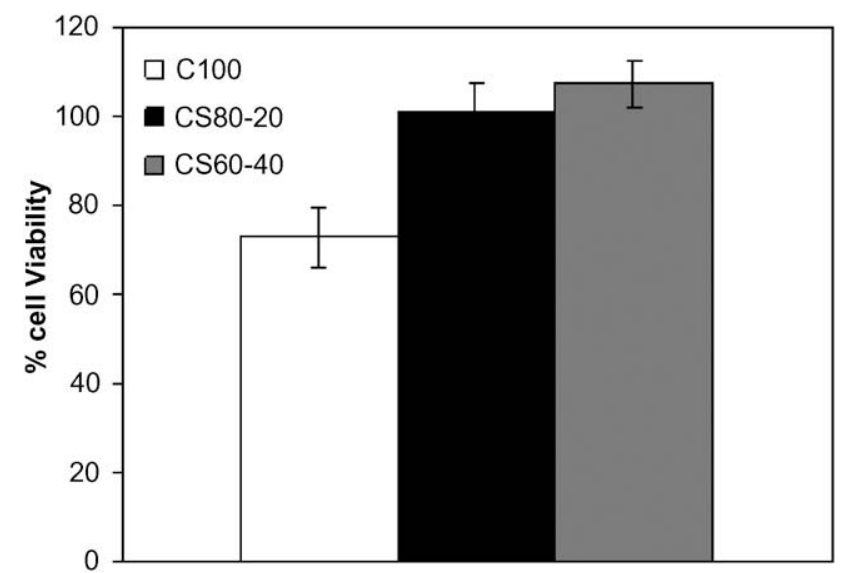

Fig. 6. Percentage of L929 viable cells determined by the MTT assay in the presence of extracts derived from the developed scaffolds. The percentage of viable cells was determined relating the optical density from the control, which is considered to have $100 \%$ viability. 
ble L929 cells in contact with C100 leachables was lower (75\%). The MTT assay suggested that the extracts from the developed scaffolds, produced by the precipitation method, were non-toxic towards mouse fibroblasts.

\subsection{Cell morphology evaluation}

The absence of cytotoxicity does not confer any information about the biocompatibility of a biomaterial [33].
In order to verify whether the developed scaffolds support the functions shared by many cell types, such as membrane integrity, adhesion to surfaces and replication, adhesion studies with the cell line L929 were performed. At the end of 7 days, regardless of the scaffold formulation, all constructs were covered with a monolayer of cells (Fig. 7). The fibroblasts had a typical spindle-shaped morphology and exhibited cytoplasmatic projections strongly attached to the scaffolds. Only in CS80-20 were rounded
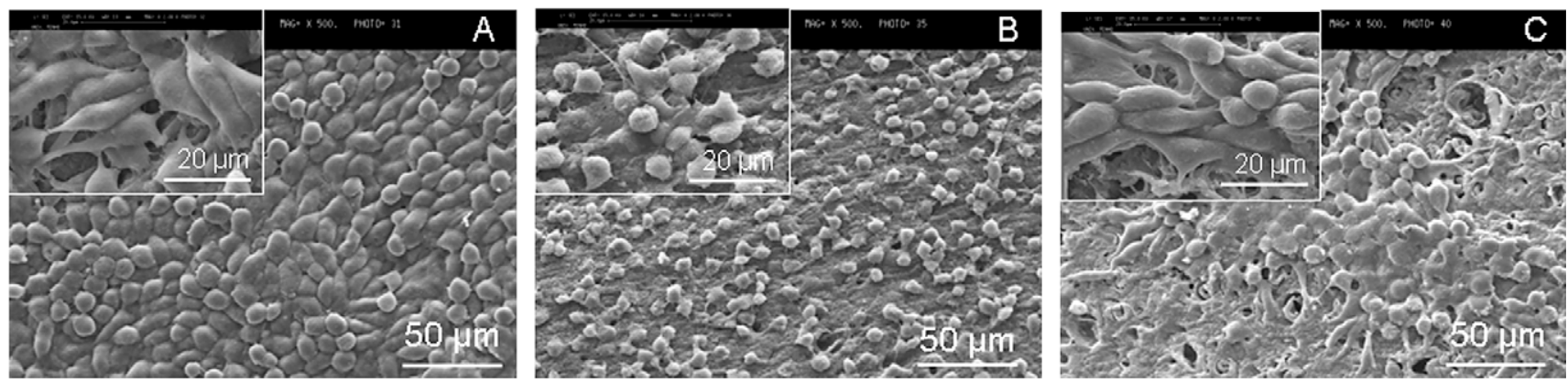

Fig. 7. SEM micrographs showing the surface the developed scaffolds: C100 (A,D), CS80-20 (B,E) and CS60-40 (C,F), before cell culture (A-C) and after 7 days of culture with L929 cells (D-F).
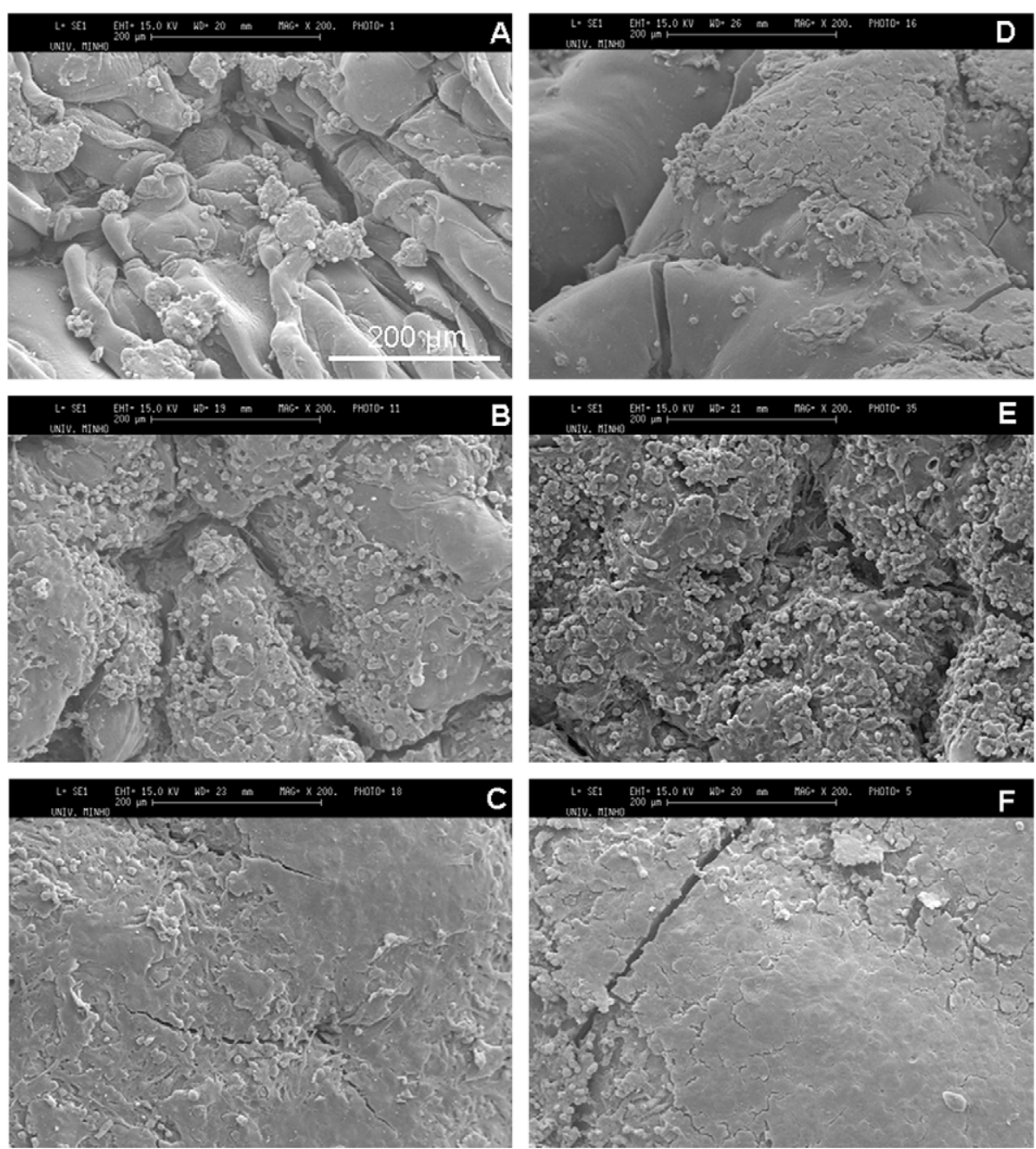

Fig. 8. SEM micrographs of C100 (A,D), CS80-20 (B,E) and CS60-40 (C,F) scaffolds cultured with osteoblast-like cells after 3 (A-C) and 7 days (D-F). The scale bar is $200 \mu \mathrm{m}$ and applies to all images. 
cells seen, denoting that they were in an earlier adhesion step (Fig. 7B). L929 cells were able to adhere, spread filopodia and stretch over the surface of the developed scaffolds. The slight toxicity of the $\mathrm{C} 100$ extracts detected in the MTT assay did not have any negative effect on the ability of L929 cells to adhere to and spread on the surface of the construct.

Cellular attachment and migration of osteoblast cells over the bone-substituting material surface are essential to obtain effective wound filling and bone tissue adaptation [34]. For that, osteoblast-like cells were seeded on C100, CS80-20 and CS60-40 and the adhesion profile, as well as the cell morphology, was documented by SEM. On day 3 of culture, SEM examination revealed osteoblasts aggregates sparsely distributed over the surface of C100 (Fig. 8A). At the same time point, the amount of cells attached to the surface of CS80-20 was greater, although cells did not cover the entire surface of the scaffold (Fig. 8B). Fig. 8C shows the surface of CS60-40 covered by a compact monolayer of osteoblasts after just 3 days of culture. At this time point it can be seen that the adhesion profile of the osteoblasts differs between chitosan scaffolds $(\mathrm{C} 100)$ and chitosan/starch scaffolds (CS80-20 and CS60-40), the growth being more homogeneous in the presence of starch. The same trend was observed at the end of 7 days. On the $\mathrm{C} 100$ scaffold the growth was limited to a number of discrete areas, which were probably the result of the expansion of the cellular aggregates seen after 3 days (Fig. 8D). On the other hand, the surface of chitosan/ starch scaffolds (CS80-20 and CS60-40) was homogeneously covered by a multilayer of osteoblast-like cells (Fig. 8E and F).Cell adhesion and spreading are influenced by the physicochemical characteristics of the underlaying solid surface [35]. CS80-20 and CS60-40 supported to the same extent the adhesion of fibroblasts and osteoblasts. However, SAOS-2 behaved in a different way on the surface of C100 scaffold. The poorer spreading on C100 may be related with the higher chitosan content, which renders the surface more hydrophilic. This impairs the adsorption of serum proteins and consequently cell adhesion [35]. Another explanation for the difference between the starch-blended scaffolds and chitosan scaffold could be the difference in topography. A higher level of roughness appears to enhance osteoblast adhesion, and subsequent proliferation and differentiation [36]. The starch granules present in CS80-20 and CS60-40 increase the roughness of the surface and therefore improve cell growth and attachment (Fig. 8E and F).

\section{Conclusions}

Scaffolds based on chitosan and starch were developed and characterised for use in bone tissue engineering applications. The results of the compressive tests showed that these materials exhibit very good mechanical properties in the dry and wet states. Enzymatic degradation caused the formation of a porous structure, indicating the poten- tial of this methodology to obtain scaffolds with in situ pore formation. These scaffolds, with in situ pore forming capability and interesting mechanical properties, seem to be advantageous when compared with other conventional materials. Biocompatibility studies showed the extracts of the developed scaffolds to be non-toxic, and CS80-20 and CS60-40 showed better osteoblast attachment than the C100 substratum. These results indicate that the incorporation of starch has a favourable effect on the interaction with osteoblasts.

The combination of properties suggests that this is a very promising way to obtain scaffolds with gradual in situ pore forming ability for bone tissue engineering applications.

\section{Acknowledgements}

This work was supported by the European NoE EXPERTISSUES (NMP3-CT-2004-500283), the European STREP HIPPOCRATES (NMP3-CT-2003-505758) and the Portuguese Foundation for Science and Technology (FCT) through POCTI and/or FEDER programmes.

\section{References}

[1] Yang SF, Leong KF, Du ZH, Chua CK. The design of scaffolds for use in tissue engineering. Part 1. Traditional factors. Tissue Eng 2001;7(6):679-89.

[2] Salgado AJ, Coutinho OP, Reis RL. Bone tissue engineering: state of the art and future trends. Macromol Biosci 2004;4(8):743-65.

[3] Hutmacher DW, Schantz JT, Lam CXF, Tan KC, Lim TC. State of the art and future directions of scaffold-based bone engineering from a biomaterials perspective. J Tissue Eng Regen Med 2007;1(4): 245-60.

[4] Suh JK, Matthew HW. Application of chitosan-based polysaccharide biomaterials in cartilage tissue engineering: a review. Biomaterials 2000;21(24):2589-98.

[5] Oliveira JM, Rodrigues MT, Silva SS, Malafaya PB, Gomes ME, Viegas CA, et al. Novel hydroxyapatite/chitosan bilayered scaffold for osteochondral tissue-engineering applications: scaffold design and its performance when seeded with goat bone marrow stromal cells. Biomaterials 2006;27(36):6123-37.

[6] Chatelet C, Damour O, Domard A. Influence of the degree of acetylation on some biological properties of chitosan films. Biomaterials 2001;22(3):261-8.

[7] Varum KM, Myhr MM, Hjerde RJ, Smidsrod O. In vitro degradation rates of partially $N$-acetylated chitosans in human serum. Carbohydr Res 1997;299(1-2):99-101.

[8] Tomihata K, Ikada Y. In vitro and in vivo degradation of films of chitin and its deacetylated derivatives. Biomaterials 1997;18(7):567-75.

[9] Ueno H, Mori T, Fujinaga T. Topical formulations and wound healing applications of chitosan. Adv Drug Deliv Rev 2001;52(2):105-15.

[10] Klokkevold PR, Vandemark L, Kenney EB, Bernard GW. Osteogenesis enhanced by chitosan (poly- $N$-acetyl glucosaminoglycan) in vitro. J Periodontol 1996;67(11):1170-5.

[11] Muzzarelli RA, Mattioli-Belmonte M, Tietz C, Biagini R, Ferioli G, Brunelli MA, et al. Stimulatory effect on bone formation exerted by a modified chitosan. Biomaterials 1994;15(13):1075-81.

[12] Sashiwa H, Saimoto H, Shigemasa Y, Ogawa R, Tokura S. Lysozyme susceptibility of partially deacetylated chitin. Int J Biol Macromol 1990;12(5):295-6. 
[13] Hankiewicz J, Swierczek E. Lysozyme in human body fluids. Clin Chim Acta 1974;57(3):205-9.

[14] Nordtveit RJ, Varum KM, Smidsrod O. Degradation of partially $N$ acetylated chitosans with hen egg white and human lysozyme. Carbohydr Polym 1996;29(2):163-7.

[15] Azevedo HS, Reis RL. Understanding the enzymatic degradation of biodegradable polymers and strategies to control their degradation rate. In: Reis RL, San Roman J, editors. Biodegradable systems in tissue engineering and regenerative medicine. Boca Raton, FL: CRC Press; 2005. p. 177-201.

[16] Muzzarelli RAA. Biochemical significance of exogenous chitins and chitosans in animals and patients. Carbohydr Res 1993;20(7):16.

[17] Gomes ME, Reis RL, Cunha AM, Blitterswijk CA, de Bruijn JD. Cytocompatibility and response of osteoblastic-like cells to starchbased polymers: effect of several additives and processing conditions. Biomaterials 2001;22(13):1911-7.

[18] Salgado AJ, Coutinho OP, Reis RL. Novel starch-based scaffolds for bone tissue engineering: cytotoxicity, cell culture, and protein expression. Tissue Eng 2004;10(3-4):465-74.

[19] Azevedo HS, Gama FM, Reis RL. In vitro assessment of the enzymatic degradation of several starch based biomaterials. Biomacromolecules 2003;4(6):1703-12.

[20] Marques AP, Reis RL, Hunt JA. The biocompatibility of novel starch-based polymers and composites: in vitro studies. Biomaterials 2002;23(6):1471-8.

[21] Salgado AJ, Coutinho OP, Reis RL, Davies JE. In vivo response to starch-based scaffolds designed for bone tissue engineering applications. J Biomed Mater Res A 2007;80(4):983-9.

[22] Tan SC, Khor E, Tan TK, Wong SM. The degree of deacetylation of chitosan: advocating the first derivative UV-spectrophotometry method of determination. Talanta 1998;45(4):713-9.

[23] Tuzlakoglu K, Alves CM, Mano JF, Reis RL. Production and characterization of chitosan fibers and 3-D fiber mesh scaffolds for tissue engineering applications. Macromol Biosci 2004;4(8):811-9.

[24] Junge W, Troge B, Klein G, Poppe W, Gerber M. Evaluation of a new assay for pancreatic amylase: performance characteristics and estimation of reference intervals. Clin Biochem 1989;22(2): 109-14.

[25] Reis RL, Cunha AM. Starch and starch based thermoplastics. In: Jurgen KH, Buschow R, Cahn W, Flemings MC, Ilschner B, Kramer
EJ, et al., editors. Encyclopedia of materials science and technology. Amsterdam: Pergamon/Elsevier Science; 2001. p. 8810-6.

[26] Muzzarelli RAA, Mattioli-Belmonte M, Miliani M, Muzzarelli C, Gabbanelli F, Biagini G. In vivo and in vitro biodegradation of oxychitin-chitosan and oxypullulan-chitosan complexes. Carbohydr Polym 2002;48(1):15-21.

[27] Brouwer J, Vanleeuwenherberts T, Ottingvanderuit M. Determination of lysozyme in serum, urine, cerebrospinal-fluid and feces by enzyme-immunoassay. Clin Chim Acta 1984;142(1):21-30.

[28] Greenwald RA, Josephson AS, Diamond HS, Tsang A. Human cartilage lysozyme. J Clin Invest 1972;51(9):2264.

[29] Petite H, Viateau V, Bensaid W, Meunier A, de Pollak C, Bourguignon $\mathrm{M}$, et al. Tissue-engineered bone regeneration. Nat Biotechnol 2000;18(9):959-63.

[30] Liu Y, Hunziker EB, Randall NX, de Groot K, Layrolle P. Proteins incorporated into biomimetically prepared calcium phosphate coatings modulate their mechanical strength and dissolution rate. Biomaterials 2003;24(1):65-70.

[31] Liu Y, de Groot K, Hunziker EB. BMP-2 liberated from biomimetic implant coatings induces and sustains direct ossification in an ectopic rat model. Bone 2005;36(5):745-57.

[32] Azevedo HS, Leonor IB, Alves CM, Reis RL. Incorporation of proteins and enzymes at different stages of the preparation of calcium phosphate coatings on a degradable substrate by a biomimetic methodology. Mater Sci Eng C 2005;25(2):169-79.

[33] Van Kooten TG, Klein CL, Kohler H, Kirkpatrick CJ, Williams DF, Eloy R. From cytotoxicity to biocompatibility testing in vitro: cell adhesion molecule expression defines a new set of parameters. J Mater Sci Mater Med 1997;8(12):835-41.

[34] Park YJ, Lee YM, Park SN, Sheen SY, Chung CP, Lee SJ. Platelet derived growth factor releasing chitosan sponge for periodontal bone regeneration. Biomaterials 2000;21(2):153-9.

[35] Horbett TA, Ratner BD, Schakenraad JM, Schoen FL. Some background concepts. In: Ratner BD, Hoffman AS, Schoen FJ, Lemons JE, editors. Biomaterials science - an introduction to materials in medicine. San Diego, CA: Academic Press; 1996. p. 133-64.

[36] Montanaro L, Arciola CR, Campoccia D, Cervellati M. In vitro effects on MG63 osteoblast-like cells following contact with two roughness-differing fluorohydroxyapatite-coated titanium alloys. Biomaterials 2002;23(17):3651-9. 